\title{
КОНСТРУИРОВАНИЕ МОДЕЛИ УЧЕБНОГО КУРСА ВЕДЕНИЯ ПРОЕКТА НА ОСНОВЕ ДИСТАНЦИОННЫХ ТЕХНОЛОГИЙ
}

\section{DESIGN OF A REMOTE TECHNOLOGY BASED TRAINING COURSE MODEL}

B. Slivkin

Summary: The article analyzes practical technologies of project crew distance learning in corporate and business training. The characteristic of distant technologies is given in this article. Here one can find variety of ITresources for distance learning. Approaches to the formation of effective learning teams are revealed. Conclusions are drawm about positive effect of distance learning in the form of enhanced self organization of participants and convenient tools for tracking overall progress.

Keywords: project training, distance learning, distant technologies, business training, corporate training, IT-technologies.

\section{Введение}

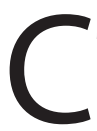
момента появления COVID-19, который вынудил правительства всего мира ввести жесткие меры изоляции, более 300 миллионов сотрудников были вынуждены работать удаленно, вдали от своих офисов. Это катапультировало компании на три-пять лет в цифровое будущее[4].

Неизбежно наступило время переосмысления обучающей функции в современной компании и выработки прикладных рекомендаций по внедрению изменений.

За последние несколько лет поведенческие экономисты, нейробиологи и когнитивные психологи добились значительных прорывов в понимании того, как люди учатся. Они обнаружили, что люди лучше всего учатся, когда тренинг персонализирован, упакован в небольшие форматы, включен в повседневную рабочую рутину и поддерживается своевременными подталкиваниями и напоминаниями[4].

\section{Изложение основного материала статьи}

Для выстраивания в компании системной работы по обучению сотрудников в текущих реалиях рационально делать пять важных шагов:

«Шаг 1. Разработать новую стратегию и сделать обучение приоритетным для топ-менеджмента.

Важно переложить ответственность за эту крити-

\author{
Сливкин Борис Сергеевич \\ аспирант, Воронежский государственный \\ педагогический университет \\ borisslivkin@rambler.ru
}

Аннотация: В статье рассматривается практические технологии дистанционного обучения проектных команд в корпоративном и бизнес-обучении. Дана характеристика "дистанционных технологий» в применении к настоящей статье. Описан ряд представленных на рынке ІТ-ресурсов для проведения дистанционного обучения. Раскрыты подходы в формировании эффективных обучающихся команд. Сделаны выводы 0 позитивном эффекте дистанционного обучения в виде усиленной самоорганизации участников и удобных инструментов для отслеживания общего прогресса.

Ключевые слова: проектное обучение, дистанционное обучение, дистанционные технологии, бизнес-обучение, корпоративное обучение, ІТ-технологии, модель учебного курса, учебный курс, цифровое будущее.

чески важную деятельность с HR на специальную L\&D функцию, которую возглавит руководитель обучения, входящий в состав исполнительного совета.

Шаг 2. Создайте новую функцию обучения и развития.

Пять основных типов ролей в будущей L\&D организации: Архитекторы обучения, Кураторы контента, Технологи обучения, Цифровые дизайнеры, Специалисты по данным (Data scientists).

Шаг 3. Включить релевантное обучение в повседневный рабочий процесс.

Внешняя мотивация включает в себя: повторение и размышление, ритм и рутина, обзор, признание и награды.

Шаг 4. Использовать возможности обучения на основе данных и науки.

Шаг 5. Создать корпоративную обучающую среду [4].»

На сегодня, при выстраивании процесса корпоративного обучения, важно учитывать современные исследования, проводимые в период пандемии. Так, Ассоциация развития талантов (ATD), в партнёрстве с платформой онлайн-обучения BizLibrary провела исследование и опубликовала отчёт E-learning: The Evolving Landscape, в котором был выявлен рост применения электронных курсов до 40 \% от всех образовательных программ в 2020 году по сравнению с 20 \% пять лет назад. Данные, 
представленные в отчёте, собраны посредством проведения онлайн-опроса 245 специалистов по развитию талантов (55 \% из них - руководители L\&D), представляющих разные отрасли [5].

Организации всё чаще применяют электронные форматы обучения с целью развития наиболее востребованных навыков у своих сотрудников. Следует отметить, что у 43 \% организаций не менее 20 \% электронных курсов являются составной частью образовательного решения, которое реализуется в смешанном формате (рис.1) [6].

Статичные электронные курсы, не требующие какихлибо активных действий со стороны слушателя, являются наиболее популярной формой. В этих решениях отсутствуют адаптивные механики, диалоговые тренажёры и иные интерактивные способы вовлечения. Такой вариант, согласно ATD, используют 87 \% опрошенных организаций [6].

Те же, кто ставит перед собой цель максимально вовлечь слушателей в процесс обучения, применяют технологии, которые перечислены ниже. Наиболее востребованными на текущий момент являются видеолекции, диалоговые тренажёры и подкасты. В краткосрочной перспективе опрошенные компании ожидают довольно значимого увеличения применения технологий виртуальной и дополненной реальности, с $6 \%$ до $24 \%$, однако велико и число тех, кто не планирует использовать данный инструмент в будущем (73 \%), что может быть связа- но с более дорогим и сложным процессом добавления подобных функций (рис.2) [6].

В целом исследование позволяет сделать вывод о том, что применение электронного обучения будет расширяться. Так в следующие пять лет электронное обучение может составлять до 60 \% портфеля корпоративных обучающих программ [6].

Для повышения эффективности обучения, очень важным является вопрос методов обучения.

Harvard Business Publishing Education опубликовала отчёт Online learning report COVID-19 Pulse Survey [7], посвящённый некоторым аспектам онлайн-образования, проводимого университетами в период пандемии. Для подготовки отчёта был проведён онлайн-опрос с более чем 800 студентами и преподавателями с бизнес-факультетов университетов разных стран и регионов [2].

Так, 57 \% студентов обеспокоены качеством онлайнобразования, которое привело к отсутствию социализации в университетских кампусах, и только $11 \%$ студентов задумываются о доступе к Интернету и технологиям для продолжения онлайн-обучения в следующем семестре. Ниже представлены основные выводы отчёта, описывающие эффективные методы и подходы к обучению и преподаванию, которые способны снизить обеспокоенность студентов и сильнее вовлечь их в дистанционный образовательный процесс:

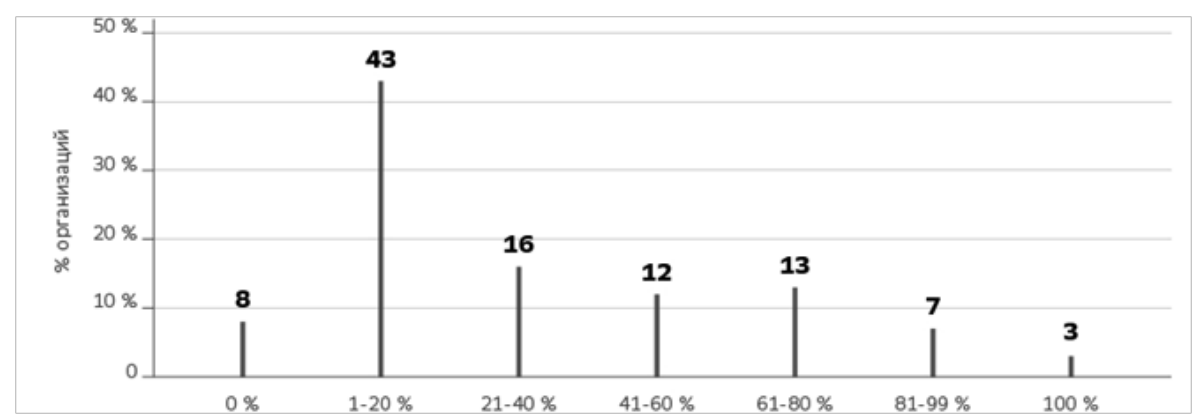

Рис. 1. Электронные курсы как часть программ в смешанном формате, \% организаций [6]

\begin{tabular}{|c|c|c|c|c|c|}
\hline & Випеолекиии & 91 & & & 4 \\
\hline & & 53 & & 30 & 17 \\
\hline & Попкасты & 51 & 13 & & 36 \\
\hline & & 6 & & & 70 \\
\hline & Дополненная реальность & 21 & & & 73 \\
\hline & & Используем & $\begin{array}{l}\text { Не используем, } \\
\text { но планируем } \\
\text { в будущем }\end{array}$ & $\begin{array}{l}\text { Не используем } \\
\text { и не планируем } \\
\text { в будущем }\end{array}$ & \\
\hline
\end{tabular}

Рис. 2. Технологии, применяемые компаниями в электронных курсах, \% респондентов 
1. Методы, используемые преподавателями в образовательном прочессе

Преподаватели бизнес-школ внедряют и используют всё больше инновационных образовательных методов, наиболее популярными среди которых являются кейсметод, используемый в своей работе 57 \% респондентов, групповая и проектная работа, которым отдают предпочтение $52 \%$ и $42 \%$ респондентов соответственно (рис.3) [2].

2. Материалы и ресурсы, используемые студентами в прочессе обучения

Видеоролики, онлайн-статьи и записанные лекции были отмечены студентами как самые эффективные обучающие материалы в онлайн (рис.4). Среди электронных образовательных площадок YouTube и бизнес-издания являются наиболее популярными образовательными ресурсами для студентов бизнес-школ (рис.5) [2].

\section{3. Темы обучения, вызывающие интерес у студентов}

B то время как половина преподавателей отметили, что тема COVID-19 и его влияние не представляет инте- реса в качестве возможной темы обучения студентов, данное направление стало вторым по популярности интереса среди студентов, предпочтение которой отдали 58 \% опрошенных. Первое место занимает тема дистанционной работы, интерес к которой проявили $62 \%$ опрошенных студентов (рис.6) [2].

Актуальность темы дистанционной работы побудила провести исследование, направленное на выявление эффективности разработанной нами модели учебного курса ведения проекта на основе дистанционных технологий.

«Под дистанционными образовательными технологиями понимаются образовательные технологии, реализуемые в основном с применением информационнотелекоммуникационных сетей при опосредованном (на расстоянии) взаимодействии обучающихся и педагогических работников [1]».

Была выдвинута гипотеза о том, что разработанная модель учебного курса с применением дистанционных технологий будет способствовать развитию самостоятельности освоения учебных курсов у слушателей в корпоративных обучающих программах, в том числе

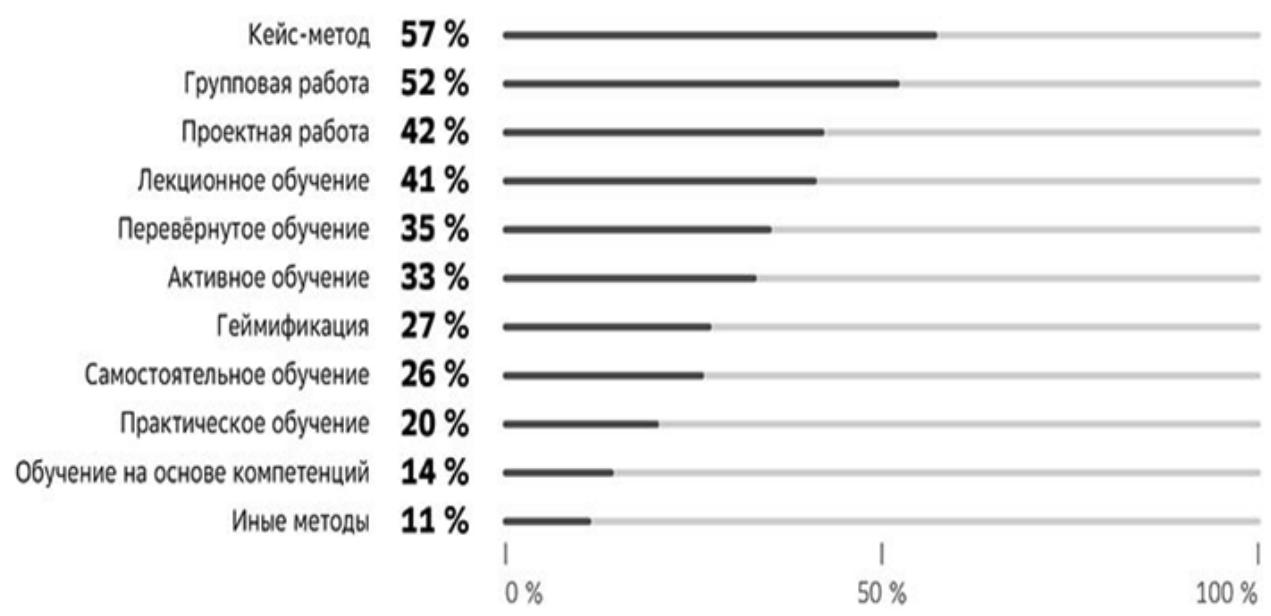

Рис. 3. Рейтинг эффективности дистанционных методов обучения, \% преподавателей

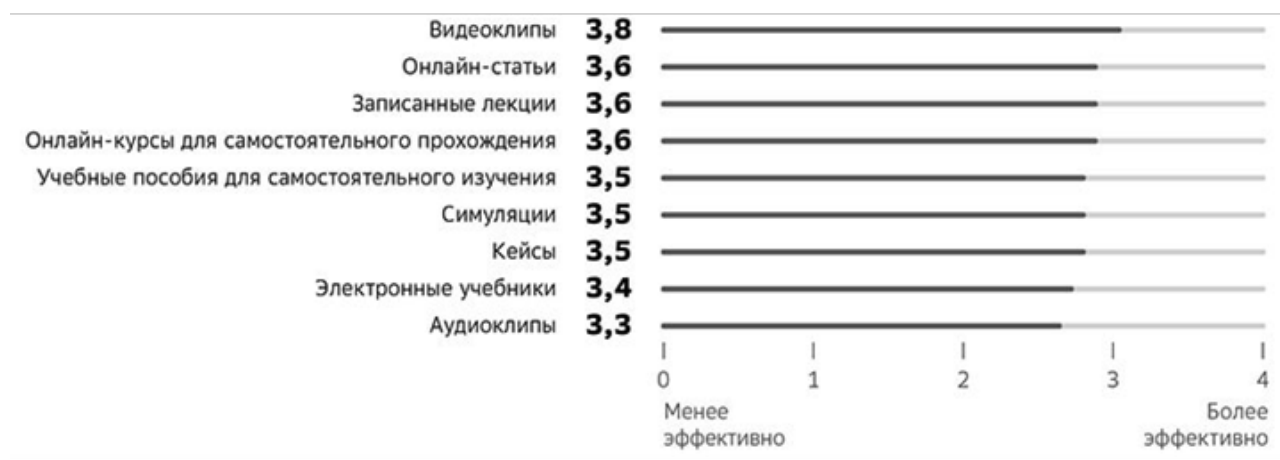

Рис. 4. Рейтинг эффективности дистанционных обучающих материалов, \% студентов 
курсов для совместной работы с преподавателем/куратором/наставником.

С целью выявления эффективности реализуемой модели обучения на базе самостоятельного структурного подразделения ПАО Сбербанк в г. Воронеже было организовано и проведено эмпирическое исследование. В исследовании приняли участие 38 человек, в том числе в контрольной группе 19 человек и в экспериментальной - 19 человек.

Эмпирическое исследование включало три этапа:

1. Констатирующий этап - проводилось анализ документов, наблюдение и входное тестирование слушателей-участников проекта на вводном занятии.

В исследовательской работе использовались следующие методики: анализ документов для выявления уровня участия в ранее реализуемых проектах слушателей с целью выявления компетенций в проектной деятельности; наблюдение за слушателями в ходе знакомства на первой встрече на проекте с целью определения уровня владения терминологией и инструментами проектной деятельности; анкетирование - для выявления неосвоенных зон проектной методологии.
2. Формирующий этап - была разработана модель учебного курса с применением дистанционных технологий и проведен комплекс занятий, способствующий отработке навыков: самостоятельного практического применения с проведением еженедельных консультаций преподавателя/наставника/куратора инструментов и технологии проектной деятельности на реализуемых проектах, анализа данных и внедрения итогов проекта в текущую деятельность с применением дистанционных технологий.

3. Контрольный этап - проверка эффективности проводимого комплекса занятий с применением дистанционных технологий с помощью повторного сбора эмпирических данных, количественный и качественный анализ результатов исследования, их интерпретация.

В таблице 1 приведена разработанная модель учебного курса с применением дистанционных технологий.

«Конечная цель любого обучения - сделать так, чтобы полученные знания приводили к качественным изменениям в жизни человека, помогали решать практические задачи. Это происходит только тогда, когда формируются новые навыки: профессиональные, мягкие или универсальные, - которые затем, после много-

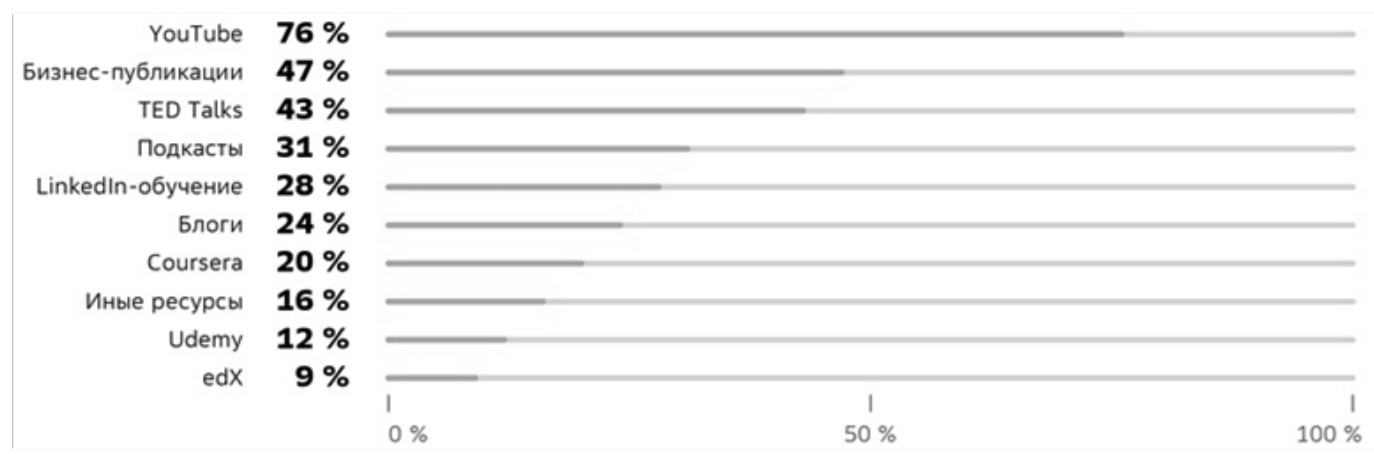

Рис. 5. Рейтинг эффективности иных обучающих ресурсов, \% студентов

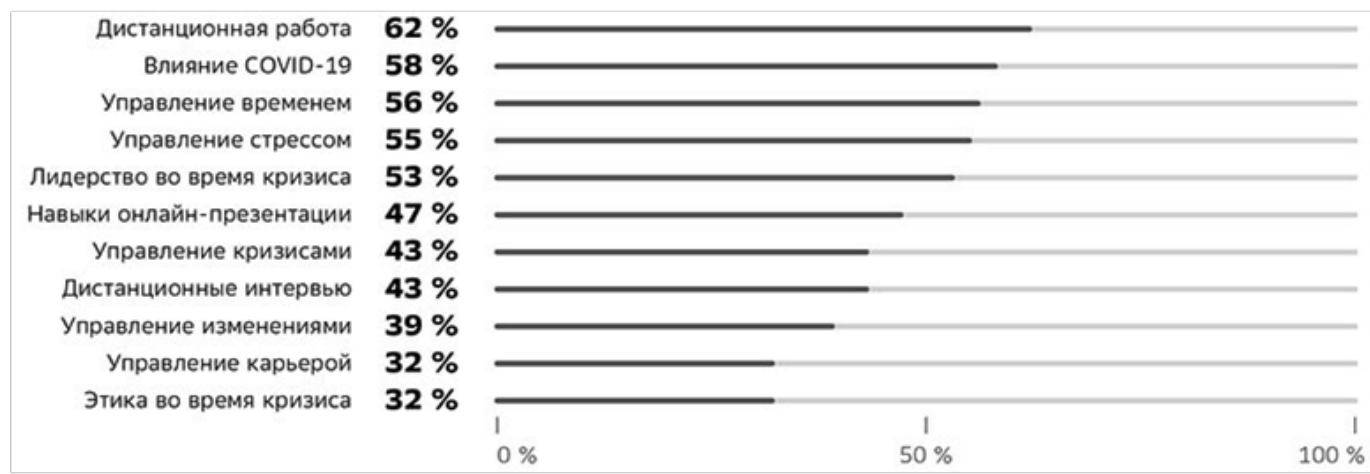

Рис. 6. Рейтинг эффективности студенческого интереса к темам обучения, \% студентов [2]. 
численных повторений, становятся привычками [3]».

На заключительном этапе реализации проектов было проведено совещание со слушателями-участниками проектов на тему «Эффективность модели учебного курса для совместной работы с применением дистанционных технологий». Участники совещания поделились опытом реализации проекта с применением дистанци- онных технологий.

\section{Обратимся к результатам исследования.}

Анализ рабочих форм проведения обучения проектной деятельности (констатирующий этап) показал, что ранее данные обучения в ПАО Сбербанк проходили только в формате офлайн, в отдельном помещении, с от-

Модель учебного курса для совместной работы с применением дистанционных технологий

Таблица 1. (на примере ведения проекта)

\begin{tabular}{|c|c|c|}
\hline Название занятия & Цели и задачи & Применяемые дистанционные технологии \\
\hline Занятие 1. Знакомство & $\begin{array}{l}\text { Цель: формирование доверительных отношений в команде про- } \\
\text { екта, выявление уровня знания инструментов ведения проекта } \\
\text { Задачи: } \\
\text { - формирование групповой сплоченности; } \\
\text { - развитие чувства уверенности в своих силах; } \\
\text { - научить договариваться, распределять задачи, смотреть на } \\
\text { проблему с разных точек зрения; } \\
\text { - определение вектора ведения проекта. }\end{array}$ & $\begin{array}{l}\text { Видеосвязь: Zoom, Google Meet, Skype, Cisco Webex } \\
\text { Meetings, Mind } \\
\text { Анкетирование/проведение опросов: Kahoot!, } \\
\text { Socrative, Plickers, Quizizz, Quizalize, Mentimeter } \\
\text { Оперативное взаимодействие: WhatsApp, } \\
\text { Telegram, Slack }\end{array}$ \\
\hline $\begin{array}{l}\text { Занятие } 2 . \\
\text { Тематика, план, проблематика, } \\
\text { исследования }\end{array}$ & $\begin{array}{l}\text { Цель: выявление и постановка проблемы, формирование } \\
\text { основных параметров проекта } \\
\text { Задачи: } \\
\text { - определить тип проекта; } \\
\text { - определить проектную методологию; } \\
\text { - определить и закрепить роли в проектной команде. }\end{array}$ & $\begin{array}{l}\text { Видеосвязь: Zoom, Google Meet, Skype, Cisco Webex } \\
\text { Meetings, Mind } \\
\text { Оперативное взаимодействие: WhatsApp, } \\
\text { Telegram, Slack }\end{array}$ \\
\hline $\begin{array}{l}\text { Занятие } 3 . \\
\text { Коммуникации, контрольные } \\
\text { мероприятия }\end{array}$ & $\begin{array}{l}\text { Цель: анализ проблемы (структурирование и приоритизация), } \\
\text { определение совместной площадки для ведения проекта } \\
\text { Задачи: } \\
\text { - создание единой среды для оперативного обмена и фиксиро- } \\
\text { вания информации по проекту командой проекта; } \\
\text { - определить правила ведения проекта для членов команды } \\
\text { проекта. }\end{array}$ & $\begin{array}{l}\text { Видеосвязь: Zoom, Google Meet, Skype, Cisco Webex } \\
\text { Meetings, Mind } \\
\text { Платформы для совместной работы с докумен- } \\
\text { тами: Miro, Notion, G Suite, Confluence, Google Colab, } \\
\text { Kaggle } \\
\text { Управление проектами: Trello, Asana, Jira, Pyrus } \\
\text { Прототипирование: Miro, Figma, Marvel, Draw.io }\end{array}$ \\
\hline $\begin{array}{l}\text { Занятие } 4 . \\
\text { Исследования }\end{array}$ & $\begin{array}{l}\text { Цель: разработка вариантов решений, определение программы } \\
\text { исследований, формулирование гипотезы } \\
\text { Задачи: } \\
\text { - выбор методологии исследования; } \\
\text { - выбор респондентов; } \\
\text { - определить формат визуализации результатов исследований. }\end{array}$ & $\begin{array}{l}\text { Видеосвязь: Zoom, Google Meet, Skype, Cisco Webex } \\
\text { Meetings, Mind } \\
\text { Управление проектами: Trello, Asana, Jira, Pyrus } \\
\text { Управление учебной групповой работой: Microsoft } \\
\text { Teams, Granatum, ТренингCпэйс } \\
\text { Презентация результатов: } \\
\text { Google Презентации, Piktochart, Canva, Prezi, Sway }\end{array}$ \\
\hline $\begin{array}{l}\text { Занятие } 5 . \\
\text { Тестирование, пилотирование }\end{array}$ & $\begin{array}{l}\text { Цель: провести тестирование/пилотирование выбранных } \\
\text { решений, дополнительное исследование } \\
\text { Задачи: } \\
\text { - отслеживать статус реализации; } \\
\text { - презентовать на дистанционных демосессиях; } \\
\text { - подвести итоги тестирования/пилотирования. }\end{array}$ & $\begin{array}{l}\text { Видеосвязь: Zoom, Google Meet, Skype, Cisco Webex } \\
\text { Meetings, Mind } \\
\text { Управление проектами: Trello, Asana, Jira, Pyrus } \\
\text { Управление учебной групповой работой: Microsoft } \\
\text { Teams, Granatum, ТренингCпэйс } \\
\text { Презентация результатов: } \\
\text { Google Презентации, Piktochart, Canva, Prezi, Sway }\end{array}$ \\
\hline $\begin{array}{l}\text { Занятие } 6 . \\
\text { Завершение проекта }\end{array}$ & $\begin{array}{l}\text { Цель: Выбор и предоставление решения, завершение проекта } \\
\text { Задачи: } \\
\text { - оформить результаты проекта как работающий прототип; } \\
\text { - определить правила тиражирования работающего прототипа; } \\
\text { - определить методы контроля соблюдения параметров эффек- } \\
\text { тивности работающего прототипа. }\end{array}$ & $\begin{array}{l}\text { Видеосвязь: Zoom, Google Meet, Skype, Cisco Webex } \\
\text { Мeetings, Mind } \\
\text { Управление проектами: Trello, Asana, Jira, Pyrus } \\
\text { Презентация результатов: Google Презентации, } \\
\text { Piktochart, Canva, Prezi, Sway }\end{array}$ \\
\hline
\end{tabular}




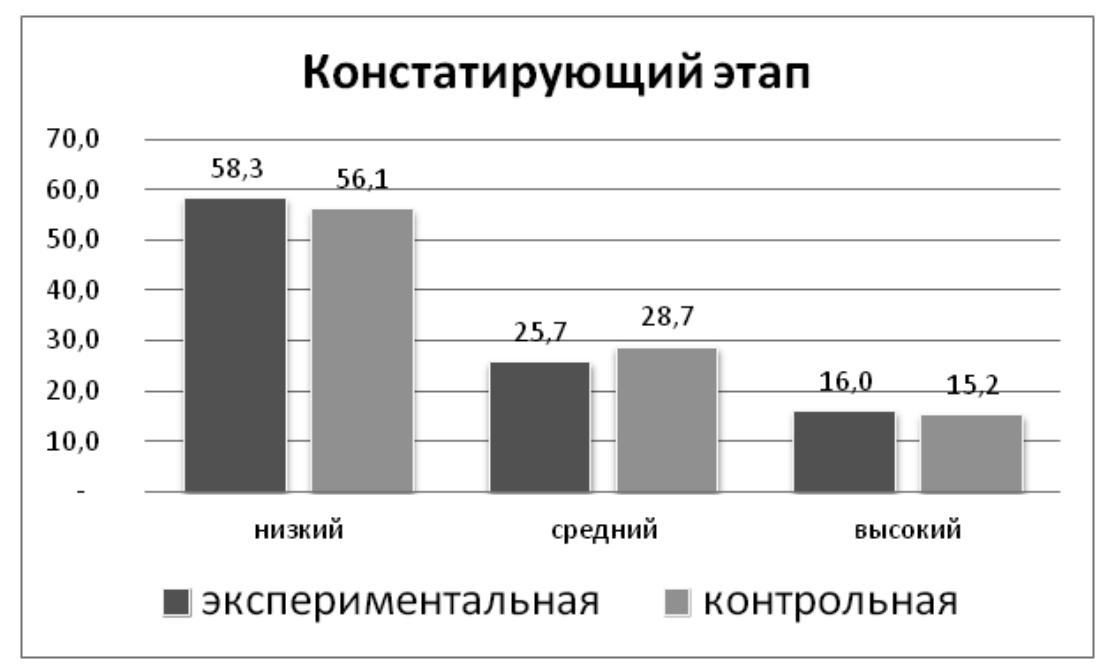

Диаграмма 1. Констатирующий этап эксперимента

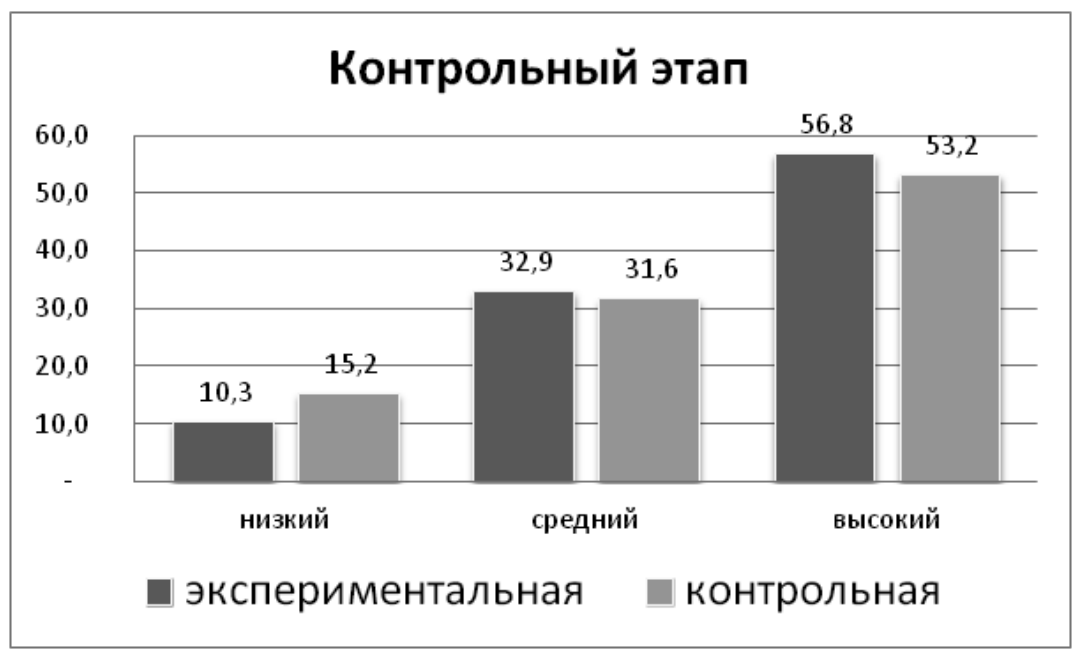

Диаграмма 2. Контрольный этап эксперимента

рывом от производства, что стало неактуальным в период пандемии. Поэтому нашей задачей было разработать Модель курса с применением дистанционных технологий, не добавляющих затрат на их использование. Для чистоты эксперимента мы провели входное тестирование экспериментальной (онлайн обучение с применением дистанционных технологий) и контрольной (офлайн обучение) групп. Результаты получили следующие (диаграмма1).

Результаты опытно-экспериментальной работы на контрольном этапе по выявлению уровня знаний проектной методологии слушателей-участников проекта показали, что высокий уровень знаний в экспериментальной группе увеличился по сравнению с полученными данными контрольного класса на $40,8 \%$ и составил $56,8 \%$. Средний показатель в экспериментальном классе $(32,9 \%)$ оказался выше контрольного (31,6\%). А низкий уровень знаний в дистанционной группе показал луч- ший результат и составил 15,2\%, тогда как в группе обучения офлайн минимальный уровень знаний составил 10,3\% (диаграмма 2).

\section{Выводы}

Проанализировав полученные данные результатов, можно сделать вывод о том, что разработанная Модель учебного курса для совместной работы с применением дистанционных технологий способствовала приобретению навыков ведения проектной деятельности у слушателей экспериментальной команды проекта.

«Организация работы над проектами органична для дистанционного формата, ведь она предполагает и самостоятельную деятельность обучающихся в удобном для них графике, и регулярную коммуникацию с преподавателем, который помогает справляться с затруднениями, оценивать результат и придерживаться графика проекта[3]». 


\section{ЛИТЕРАТУРА}

1. Федеральный закон от 29 декабря 2012 г. N 273 «06 образовании» (сучетом изменений и дополнений).

2. Онлайн-образование в период COVID-19: что думают преподаватели и студенты [Электронный ресурс]. - Сбер Университет. - 22.12.2020.URL: https://sberbank-university.ru/edutech-club/pulse/trendy/4610/ (дата обращения: 08.05.2021)

3. Ширшова Л. Эффективный переход в дистанционное обучение // EduTесh. Информационно-аналитический журнал, Корпоративный университет Сбербанка, 2020.Спецвыпуск, июнь. С.27-44

4. Эндрю Дайер. Почему пришло время приносить обучение в C-Suite [Электронный ресурc]. - 14.07.2020. - URL: https://www.bcg.com/en-ru/ publications/2020/why-it-is-time-to-bring-learning-to-the-c-suite (Дата обращения: 28.04.2020)

5. Электронное Обучение: Эволюционирующий Ландшафт. Отчет об исследовании [Электронный ресурс]// - ATD Research - август 2020. URL: https://www.td.org/research-reports/e-learning-the-evolving-landscape (дата обращения: 08.05.2021)

6. Эксперты АТD подтверждают укрепление роли электронных курсов [Электронный ресурс]. - Сбер Университет. - 22.03.2021.URL: https://sberbank-university.ru/edutech-club/pulse/trendy/8415/ (дата обращения: 08.05.2021)

7. Online learning report covid-19 pulse survey [Elektronny resurs]// - URL: https://s3.amazonaws.com/he-product-images/docs/Higher_Education_ Online_Learning_Report_Aug2020.pdf?cid=email\%7Celoqua\%7(8-26-20-back-to-school-online-teaching-resources-project-ace-webinar-reg-andedu\%7(617648\%7Cthemed-broadcast\%7Ceducator\%7Cvarious\%7Caug20202001\&acctID (дата обращения: 08.05.2021)

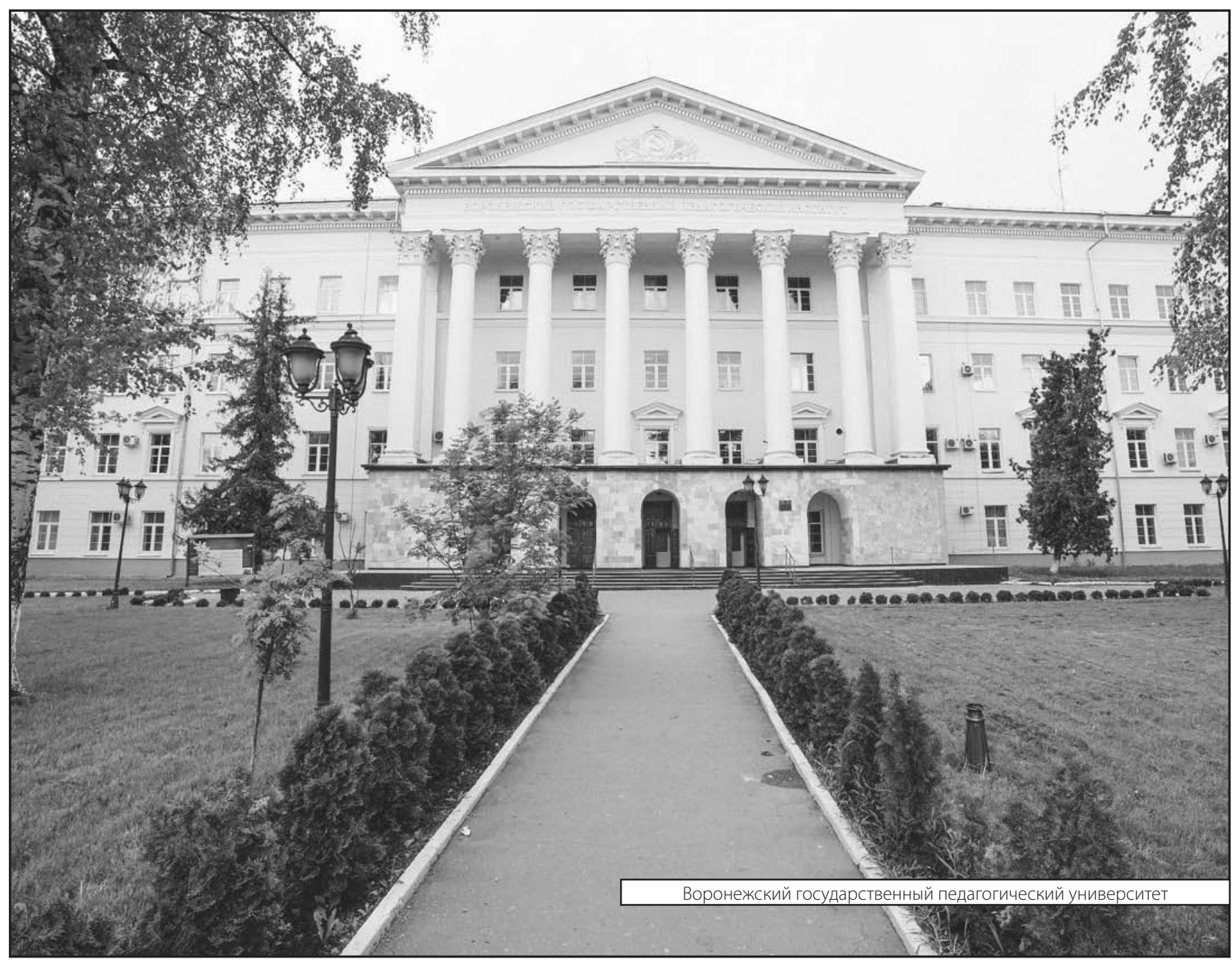

